\title{
Anticipatory Savoring and Consumption: Just Thinking about That First Bite of \\ Chocolate Fills You Up Faster
}

\section{IAIN BLACK}

Dr. Iain Black is a Reader in the School of Management and Languages, Heriot Watt University, Edinburgh, Scotland, EH14 4AS, Tel: +44 1313803 I.R.Black@HW.ac.uk

\section{CHARLES S. ARENI}

Charles S. Areni is a professor of marketing and the Macquarie Graduate School of Management, Macquarie University, North Ryde NSW 2109 Australia, Tel: +61 29850 9085, Fax: +61 29850 8630, Charles.Areni@mgsm.edu.au

This is the peer reviewed version of the following article: Black, I. R. and Areni, C. S. (2016), Anticipatory Savoring and Consumption: Just Thinking about That First Bite of Chocolate Fills You Up Faster. Psychology and Marketing, 33: 516-524, which has been published in final form at https://doi.org/10.1002/ mar.20894. This article may be used for non-commercial purposes in accordance with Wiley Terms and Conditions for self-archiving. 


\section{Anticipatory Savoring and Consumption: Just Thinking about That First Bite of Chocolate Fills You Up Faster}

Two laboratory studies examine how consumers adjust their eating to the size of the portion they expect to receive. Participants who knew in advance that they would receive six pieces of chocolate waited less time before eating each piece and ate more pieces than participants who expected to receive only two pieces when they started, even though both groups were ultimately offered six pieces. In the second study, natural variance in how long participants waited before tasting the chocolates was negatively related to how many additional pieces they thought they could eat after finishing the last piece. These results suggest that increasing the interval prior to taking the first bite of a piece of chocolate reduced overall consumption. When consumers focus their attention on eating, the interval before taking the first bite captures anticipatory savoring - psychologically looking forward to the actual consumption experience.

Keywords: Anticipation, Savoring, Food Consumption, Satiation, Eating Rate, Caloric Intake, Portion Size 
Numerous laboratory and field experiments have found a relationship between eating rate and the amount eaten (Andrade et al., 2008; Rozin et al., 2003; Ziljstra et al. 2008). Moreover, the rate of eating influences the subjective experience of satiation - how full one feels after consuming a given amount (Mars et al., 2009; Zijlstra et al., 2009). For example, consumers who are served small portions eat more slowly, consume less overall, yet do not necessarily feel less full than consumers served large portions (Areni \& Black, 2015; Rolls, et al., 2002; Fisher, Rolls, \& Birch, 2003; Rolls, et al., 2004; Rozin, et al., 2003; Wansink, et al., 2005; Zlatevska, Dubelaar \& Holden 2014), suggesting that portion size not only influences the amount eaten, but also how quickly consumers begin to feel full. Research has also found that larger portions increase eating rates (Fisher, Rolls, \& Birch, 2003; Rozin, et al., 2003), the number of chews per piece. Portion size also affects the amount of attention given to the sensory experiences of eating (Areni \& Black, 2015, Sevilla \& Redden, 2014; Wansink, Painter \& North, 2005).

Additional studies have found a positive relationship between eating rate and caloric intake in the absence of manipulating portion size (Ziljstra, et al., 2008), suggesting individual differences in eating behaviors influence how quickly one begins to feel full. However, research is still required to clarify conflicting results and explanations regarding the relationship between specific eating behaviors, eating rate, and the amount of food consumed (Areni \& Black 2001; Galak, Kruger \& Loewenstein, 2013; Kral, 2006). In particular, why does eating rate influence caloric intake, and which specific eating behaviors drive this relationship? This research question is even more vital given recent conflicting research findings regarding how the interval in between pieces, or more generally units of food, influences overall caloric intake.

Galak, Kruger and Loewenstein (2013) reported that eating more slowly-specifically taking longer in between pieces of chocolate - increases caloric intake, so encouraging consumers to slow down if they want to enjoy more of their favorite foods. They explained this finding in terms of dishabituation (Epstein et al., 2009). Habituation is an intuitive idea wherein 
people eventually stop consuming something because they become full, bored, physically exhausted, etc., but as time passes the habituation abates and the desire to consume returns (McAlister, 1982). The tendency to recover one's desire over time is called dishabituation (Epstein et al., 2009), and research suggests that consumers underestimate how quickly it can occur (Galak et al., 2013). Hence, whether one is watching television, playing a computer game, or eating chocolates, even relatively brief pauses lead to dishabituation, which increases the desire to consume more (Galak et al., 2013; Nelson \& Meyvis, 2008).

In terms of eating behavior, dishabituation often occurs in between units of food (i.e., pieces, bites, forkfuls, etc.). The longer a diner waits in between units, the more they recover their appetite before resuming eating (i.e., dishabituation). Consistent with this explanation, research has shown that humans tend to take increasingly longer pauses in between bites as their meal progresses, presumably because it takes longer for dishabituation to occur the more one has already eaten. At some point in the meal, the period required for dishabituation becomes so long that the diner simply ends the meal (Allison \& Castellan, 1970).

Another related finding is that the caloric intake during a meal is positively related to the variety of foods in that meal (Raynor \& Epstein, 2001). A variety of offerings allows the eater to take longer pauses in between bites of any one food (i.e., while eating other foods in the meal), hence recovering their appetite for that food. That is, food habituation is sensory attribute specific (Inman, 2001; Rolls, 1986). Diners who are completely satiated on one type of food, may find plenty of appetite left for another food that smells and tastes quite differently; hence, the ability to eat dessert even after a large amount of food has been consumed during earlier courses of the meal.

Although it is possible that dishabituation occurs in between bites of small pieces of chocolate, these intervals are very short. Previous research suggests that it is the period of time in between pieces, or units, of chocolate that will determine the extent of dishabituation (Galak et 
al., 2013; Geier et al., 2006). The implication is that the pre-unit time (PUT) before eating a piece of chocolate will be positively related to overall caloric intake. The longer a consumer waits before the next piece of chocolate, the more they will be able to eat.

However, participants in the Galak et al. (2013) experiments were offered a substantial number of units, or pieces of chocolate, and eating was accompanied by a distraction task. They either watched cartoons or performed a simple computer task while eating, with experimental instructions implying that the chocolates were incidental to focus of the research. While neither distraction task was onerous, each likely prevented the participants from devoting their undivided attention to the sensory experiences of eating the chocolates. And given the results of Areni and Black (2015), the expectation of many more pieces to come may have minimized the amount of attention directed at any one piece.

This has important implication for understanding the relationship between eating rate and amount consumed, because anticipatory savoring (Bryant \& Veroff, 2007) offers a different theoretical account of the relationship between PUT and caloric intake. Savoring involves a focus of attention on the sensory input of a consumption experience. It involves a "heightened awareness" that makes consumers "more fully conscious of the pleasurable things we see, hear, smell, touch, or taste" (Bryant \& Veroff, 2007, p. 6). Savoring prolongs and intensifies the enjoyment of a consumption experience by drawing attention to sensory aspects of the experience that might otherwise be missed (Bryant, 2003).

Research has shown that consumers often refer to dining when prompted to recall experiences that they have savored, describing gourmet foods, or rarely encountered cuisines associated with vacation travel (Bryant \& Veroff, 2007). More specifically, eating fine chocolate is a consumption experience that particularly lends itself to savoring (Le Bel \& Dube, 2001 cited in Bryant \& Veroff, 2007). Areni and Black (2015) reported the results of three laboratory experiments showing that eating rate was negatively correlated with the number of additional 
chocolates participants thought they could eat after tasting two pieces. Eating rate was linked to the number of chews per piece of chocolate, which mediated its effect on the number of additional pieces participants estimated they could consume later.

However, the notion of anticipatory savoring suggests that PUT - the amount of time one waits prior to taking the first bite of a piece of chocolate - will be negatively correlated with overall caloric intake. Anticipatory savoring can occur prior to actual consumption as a strategy consumers use to maximize the pleasure of looking forward to an event expected to be pleasurable (Loewenstein, 1987; Bryant, 2003). Often, the pleasure experienced in anticipation of a consumption event exceeds that experienced during actual consumption (Areni, 2008; Mitchell et al., 1997). Hence, a person who likes chocolate, and who is just about to taste a piece expected to be enjoyable, can enhance the overall pleasure derived from the tasting it, by contemplating the experience prior to taking the first bite.

In this context, anticipatory savoring increases PUT, which slows overall eating speed (Areni \& Black, 2015; Fisher et al. 2003), and ultimately decreases caloric intake (Areni \& Black, 2015; Mars et al., 2009; Rozin et al., 2003). However, in finding a negative relationship between eating time and amount eaten, Areni and Black (2015) did not specifically examine the period of time in between pieces, or units, of chocolate (Galak et al., 2013). The research reported below isolates PUT as a specific eating interval in order to contrast dishabituation and savoring as explanations for the relationship between eating rate and caloric intake.

The literature suggests at least two factors that influence whether dishabituation or anticipatory savoring better accounts for the relationship between PUT and caloric intake. When eating a particularly enjoyable food is unencumbered by a secondary distraction task, the interval in between units is more likely to capture anticipatory savoring rather than dishabituation, and the relationship between PUT and overall caloric intake will be negative rather than positive. In 
essence, anticipatory savoring requires contemplating the eating experience in advance prior to actual consumption. This contemplation is easier when attention to the chocolate is undivided.

Another important difference between savoring and dishabituation as explanations for the relationship between PUT and caloric intake is that the former tends to occur when the consumption quantity is limited (e.g., Areni \& Black, 2015), whereas the latter is more likely to be observed when the consumption quantity is larger (e.g., Galak et al., 2013). Large portions signify that there is more to come, so consumers have less incentive to pay attention to any given piece. By contrast, when portions are smaller, the amount of pleasure derived from actual consumption is more limited, so consumers are more motivated to compensate by adding to the enjoyment of the experience via anticipatory savoring (Areni \& Black, 2015).

Hence, in order to prompt savoring, the first study reported below manipulates how many pieces of chocolate participants expected to receive when they started eating, while holding the amount of chocolate actually available for tasting constant. The idea is that consumers who expect to receive a smaller portion will be prompted to savor the initial pieces more than consumers who expect to receive a larger portion from the outset. The following research hypotheses are tested.

H1: Consumers who expect to be offered six pieces of chocolate from the outset eat more than consumers who expect to receive two pieces when they begin eating but are eventually offered all six pieces.

H2: Consumers who expect to be offered six pieces of chocolate from the outset wait shorter intervals before each piece than consumers who expect to receive two pieces when they begin eating but are eventually offered all six pieces.

H3: PUT is negatively correlated with the amount eaten. 
H4: The effect of expected portion size on amount eaten is mediated by PUT.

\section{Study 1}

\section{Sample and Procedure}

Forty-six students (31 female, 15 male) responded to an advertisement, posted on a departmental website, entitled "Research Participants: Chocolate tasting study". The advertisement explained that "The study is only open to students who like chocolate. All you have to do is taste some pieces of chocolate and answer a series of questions about them. You will be paid $£ 5$ for participating.” They were also instructed not to eat anything at least one hour before the session as “There's no sense getting full before you taste the delicious chocolates!' Upon arriving at the designated room, participants were encouraged to eat as much chocolate as they like, but the experimenter emphasized that they should not overeat and make themselves sick. These instructions were intended to eliminate any demand effects regarding the "normal" or "appropriate" amount of chocolate to consume.

The experimenter placed a covered plate on the table, and removed the lid to reveal two chocolates. The pieces used were gourmet Belgian chocolates which were identical in size, design, color and flavor. Participants were then told "You will taste them one at a time. I will place the first piece on the tasting plate. I'll leave the room so you don't have me watching whilst you eat, and will return in two to three minutes. ” These instructions made participants aware that the timing of the presentation of each piece of chocolate was determined by the experimenter, hence eliminating any motivation for participants to alter their eating rate due to possible demand effects of the experimental setting (i.e., larger portions implying that they should eat faster to finish on time).

The experimenter then continued "We will then repeat the procedure with the next 
piece of chocolate. After the last piece you will be asked to complete a brief questionnaire about the chocolates. Do you have any questions?" After placing the first piece of chocolate on the tasting plate the experimenter covered the remaining piece on the display tray and left the room with it. For the experimental conditions after the initial two pieces, the remaining four pieces were brought into the room one at a time, with each piece covered on the presentation plate until the experimenter revealed it.

In the designated room, a small digital video camera was placed at 45 degrees to the participant's seat to capture their behavior whilst eating the chocolates (see Forde et al., 2013; Hill \& McCutcheon, 1975). Two judges, blind to the hypotheses of the researchers, watched the video-recordings and recorded the amount of time passing before the first bite of each presented piece, in units of tenths of seconds. Cohen's Kappa was 0.97, indicating a very high level of inter-coder reliability. The few discrepancies that did emerge were resolved by having one of the researchers meet with the coders and resolve the disparities via discussion, while watching the corresponding videos.

\section{Independent Variable}

The manipulation of expected portion size was based on the timing of when participants learned of the additional pieces available for tasting after the two initially appearing on the display tray. In the large expected quantity condition participants were told of the additional pieces prior to tasting the first piece, whereas in the small expected quantity condition they were told only after tasting the second piece.

\section{Dependent Variables}

Pre-unit time (PUT): PUT was the time in between when the experimenter closed the door behind them and when the participant took the first bite of the chocolate, averaged 
over all the pieces eaten (Rugh, 1972).

Amount consumed: Participants were allowed to discontinue eating at any point in the study, but were encouraged to eat as much as they liked, without getting sick or uncomfortable. The dependent variable was the amount of chocolate consumed, expressed in units of pieces. If participants did not finish a piece, the remaining amount was weighed and expressed as a percentage in tenths.

\section{Results}

In order to check the manipulation of expected quantity, participants were asked "How many pieces of chocolate did you expect to receive just before you tasted the first piece?" with an open-ended response scale. Results indicated that participants in the larger expected quantity condition expected to receive more chocolates $(M=5.07)$ than participants in the smaller expected quantity condition $(M=3.82)$ as intended $\left(\mathrm{t}_{1,45}=2.06\right.$, $\mathrm{p}<.05)$. Additional analyses indicated that PUT $(\mathrm{W}=0.897, \mathrm{p}<.0001)$ and amount eaten $(\mathrm{W}=0.744, \mathrm{p}<.0001)$ were not normally distributed.

Log transformations were successful in achieving normality for PUT (W $=0.982, p$ $<.40$ ). However, the modal number of chocolates eaten was the maximum of six, making it impossible to transform the distribution to achieve normality (Afifi \& Clark, 1984). In addition, since participants in both conditions were offered a maximum of six pieces of chocolate, it is possible that the data was truncated for participants eating all six pieces (i.e., six could really mean six or more). Hence, the dependent variable was dichotomized to capture participants who finished all six pieces (1) versus those who did not (0).

A chi-squared test was performed on a cross-tabulation of expected quantity with whether a participant finished all six pieces. Results indicated that participants who 
initially expected to receive two pieces were less likely to finish all six pieces ( 5 of 22) than participants who expected to receive six pieces from the outset $(21$ of 24$)\left(\chi^{2}=\right.$ 19.60, $\mathrm{p}<.0001)$. Hypothesis 1 was supported.

Previous studies finding a positive relationship between eating rate and caloric intake, often report that participants' subjective sense of fullness was not related to the actual amount consumed (Rolls, et al., 2002; Rolls, et al., 2004; Wansink, et al., 2005), and research on savoring suggests that one of its essential functions is to increase the rate of satiation such that consumers can make do without for longer afterwards (Areni \& Black, 2015; Bryant \& Veroff, 2007). In order to examine this possibility, after finishing the chocolates, participants were asked "How many more pieces of chocolate like the ones you just tasted do you think you could eat right now?" using an open-ended response scale. Results indicated that the number of additional pieces participants thought they could consume afterward was similar in the large $(M=0.58)$ and small $(M=0.68)$ expected quantity condition $(\mathrm{F}(1,44)<$ 1). So, savoring reduced the actual amount eaten without affecting how full participants felt when they finished.

In order to test hypothesis 2, a one-way ANOVA was performed with expected quantity as the independent variable and PUT as the dependent variable. Results indicated that PUT was longer for participants who initially expected to receive two pieces of chocolate $(M=19.30)$ compared to participants who expected to receive six pieces from the outset $(M=14.59)$. Even though both groups knew they had to wait for three minutes for the experimenter to return to the room to present the next piece, those expecting to receive only two pieces waited almost five seconds longer on average before tasting the chocolate $(\mathrm{F}(1,45)=8.74, \mathrm{p}<.005)$. Hypothesis 2 was supported.

In order to test hypothesis 3, a logistic regression was run with PUT as the independent variable and whether participants finished all six pieces as the dependent 
variable. Results indicated that the longer participants took on average before tasting the next piece of chocolate, the less likely they were to finish all six pieces $\left(b=-3.46, c^{2}=7.18\right.$, $\mathrm{p}<0.008)$. Hypothesis 3 was supported.

In order to test Hypothesis 4, that PUT mediates the effect of expected portion size on amount eaten, the products of coefficients Sobel test was performed (Soper, 2015). The first step was to run a regression with the potential mediator, PUT, as the dependent variable and the independent variable, expected portion size, as the predictor variable (Baron \& Kenny, 1986). The prior test of hypothesis 2 establishes that this relationship must be significant ( $\alpha$ $=-0.28, \mathrm{t}(1,44)=-2.96, \mathrm{p}<.005)$. Next, both the independent variable, expected portion size, and the mediator, PUT, were included as predictors of whether participants finished all six pieces or not to establish that PUT is a predictor independently of expected portion size. However, this effect was only marginally significant $(\beta=-0.30, \mathrm{t}(1,43)=-1.81, \mathrm{p}<0.08)$. When the four parameters $\alpha, \beta, s_{\alpha}, s_{\beta}$ were included, the Sobel test indicated only a marginal result $(\mathrm{t}=-1.55, \mathrm{p}<.07)$. Hence, hypothesis 4 is not supported.

\section{Discussion}

Study 1 examined how the expected size of a portion of chocolates influences eating behavior, eating rate and amount consumed. Participants who knew in advance of the additional pieces of chocolate to follow increased their eating rate and consumed more compared to participants who learned of the additional pieces only after consuming the initial two. Participants expecting a smaller portion of chocolates had longer PUTs, allowing them to experience the subjective state of being full sooner than participants initially expecting a larger quantity from the outset.

When eating is mindful and attention paid to the task, PUT may be better cast as 
reflecting anticipatory savoring (Loewenstein, 1987) of this highly pleasurable experience (Bryant \& Veroff, 2007). Only those participants expecting a larger volume are able to adjust their eating behavior, including eating rate (Fisher et al. 2003) to balance, gaining pleasure and satiation from the chocolates, whilst avoiding complete satiation before all six pieces have been finished (Angeles-Castellanos et.al., 2008). As anticipatory savoring increases the pleasure of consuming each piece of chocolate (via time spent before eating) (Bryant \& Veroff, 2007), the rate of satiation increases, so participants anticipating a small portions in advance were not able to consume as many chocolates.

However, the results of Study 1 are limited by the following factors. The experiment was conducted in a controlled lab setting, which relied on a rather contrived manipulation of expected portion size. It is not clear where, and under what circumstances consumers would encounter such a situation in actuality. Study 2 relies on natural variation in PUT as an individual difference variable rather than an experimental manipulation (Galak et al., 2013).

Second, the need to dichotomize the dependent variable (the amount eaten) in Study 1, may have affected the results in unanticipated ways. For example, could the participants in the large expected portion conditions who finished all six pieces have consumed even more if given the chance? Was their caloric intake effectively truncated by the experimental procedure? Or conversely, participants who expected a larger portion from the outset feel more obligated to finish al six pieces even if they felt full earlier in the sequence? ${ }^{1}$

Study 2 therefore relies on a continuous dependent variable that does not involve eating a large number of chocolates. Prior research has established that consumers are reasonably accurate in estimating how much food they will eat prior to commencing (Stubbs, et al., 2000). Hence, Study 2 offers all participants only two pieces of chocolate and relies on the subjective measure of how many more pieces they think they can consume afterwards to

\footnotetext{
${ }^{1}$ The authors would like to thank one of the reviewers for insightful comments on Study 1 which guided the design of Study 2.
} 
capture the natural covariance in how PUT influences the amount of chocolate consumed (see Areni \& Black, 2015).

\section{Study 2}

\section{Sample and Procedure}

The procedure was the same as Study 1, with some minor variations to allow for each participant to receive two chocolates Sixty-seven students (52 female, 15 male) responded to the same advert though data collection took place in a subsequent academic year and care was taken to ensure students did not take part in both studies. The study room was set up in the same way as study one, including the presence and position of a digital camera but this time only two pieces of chocolate (of the same type as used in study one) were underneath the covered plate.

A cover story regarding the trial of "safe study protocols" was used to disguise the purpose of the camera and to encourage natural eating behaviors and after consent was obtained and the video camera started, the experimenter removed a cloche to reveal the two identical chocolates. Participants were then told: "You will taste 2 pieces of chocolate today, you will taste them one at a time. I will place the $1^{\text {st }}$ piece on the tasting plate, I will leave the room and return in 2 to 3 minutes. Then we will repeat the procedure with the next piece of chocolate." By informing participants that the experimenter would control the presentation timings, the motivations to alter eating rate due to possible experimental setting demand effects such as the portion size indicating the appropriate eating rate, were removed. The experimenter then placed the first chocolate on the empty plate, left the room and returned, always after three minutes. The process of eating was repeated with the second 
pieces after which the participants completed a questionnaire containing measures of satiation, were debriefed and asked not to discuss the purpose of the study.

Eating behavior was recorded and analyzed using the same procedures in study one, though two different judges, again blind to the hypotheses of the researchers, watched the recordings and recorded the (same) time intervals. These direct measures were aggregated to create the independent variables.

\section{Independent Variables}

Pre-unit time (PUT): PUT was measured in the same way as for study one and represents the time between when the experimenter closed the door behind them and when the participant took the first bite of the chocolate, averaged over the pieces eaten (Rugh, 1972).

\section{Dependent Variable: Felt Satiation}

After participants finished the second piece of chocolate, they were asked about their perceived capacity to consume additional pieces. The questionnaire prompted participants with three successive items "If you could taste additional pieces similar to the ones you just tried, how many additional pieces of chocolate would you like to try?", "How many additional pieces could you eat right now?," and "How many additional pieces do you desire right now?", each with an open-ended response format requiring the participant to write a numeral.

Exploratory factor analysis revealed a single factor solution with each item exhibiting a loading of great than 0.80 and a communality index of greater than 0.63 . Hence, the measure of satiation was the mean of the responses to these three items. The responses ranged from zero to eight, but the distribution exhibited a positive skew (Skewness $=1.69, W=.87, \mathrm{p}<$ .0001), which often occurs with caloric intake data (Vohs \& Heatherton, 2000). A log 
transformation of the data corrected this skew (Skewness $=0.17, W=.98, \mathrm{p}<.49$ ), and this constituted the dependent variable reported in the analyses below (see Afifi \& Clark, 1984).

\section{Results}

Given that only two pieces were eaten, in order to test hypothesis 3, a stepwise regression was run with pre-unit time for the first (PUT1) and second (PUT2) piece as the predictor variables, and satiation as the dependent variable. Tests for normality indicated a positive skew in the data for PUT1 (Skewness $=2.44, W=.79, \mathrm{p}<.0001$ ), and PUT2 (Skewness $=3.62, W=.66, \mathrm{p}<.0001)$. Log transformations largely eliminated the skewness for PUT1 (Skewness $=-0.31, W=.99, \mathrm{p}<.74)$, and PUT2 $($ Skewness $=0.17, W=.99, \mathrm{p}<$ $.99)$, so the transformed variables were used in the analysis reported below.

Results of the stepwise regression indicated that it was mainly the waiting time prior to starting the second and last piece (PUT2) that predicted how many additional pieces participants thought they could eat afterward $(\beta=-.14, F(1,63)=4.15, \mathrm{p}<.05)$. PUT1 was not a significant predictor at $\alpha=.15$. In essence, the length of the interval in between when the second and last piece of chocolate was presented and when participants began eating it, predicted how many additional pieces they thought they could eat afterwards. The longer they waited, the less they thought they could eat afterward.

\section{Discussion}

Overall, these results support hypotheses 3 . When participants were served a relatively small number of chocolates, and were presented with what they thought would be the last piece, they spent longer contemplating the chocolate before taking the first bite. Although 
this interval was not explicitly linked to savoring processes, prior research suggests such intervals are associated with increased attention to sensory inputs. Indeed, participants spent much of the PUT interval looking at, and even smelling the chocolate, suggesting that they were focused on the tasting experience soon to follow (Areni \& Black, 2015).

\section{General Discussion}

The results of two experiments show that the interval of time a consumer waits prior to taking the first bite of a piece of chocolate is negatively correlated with the amount of chocolate actually eaten (study 1), or the amount the consumer believes they could eat (study 2). These results, which suggests that the pre-unit wait time (PUT) captures savoring, are consistent with several earlier studies showing a positive relationship between eating rate and amount consumed, or a positive relationship between eating rate and how subjectively full consumers feel after consuming a given amount (Andrade et al., 2008; Mars et al., 2009; Rozin et al., 2003; Ziljstra et al. 2008; Zijlstra et al., 2009). However, these results run counter to those of Galak et al. (2013), who reported a positive relationship between the average interval between pieces of chocolate and the overall amount consumed, due to dishabituation.

Collectively, these studies suggest that PUT is more likely to capture savoring (a) when the consumption experience is unique or otherwise notably enjoyable, (b) when the amount to be consumed is small (i.e., less than complete satiation) rather than large, and (c) when consumers are focused on the consumption experience. By contrast, PUT may capture dishabituation when (d) the consumption experience is typical or mundane, (e) the amount to be consumed is large (i.e., beyond the point of satiation) rather than small, and (f) consumers are distracted from the consumption experience. Future research would 
benefit from an explicit test of how these factors affect the observed relationship between PUT and the amount consumed.

In explaining these effects more widely, savoring may be an adaptive mechanism that psychologically expands a limited quantity of food so there is less desire for more after eating (Quoidbach et al., 2010). Perhaps in times when food was scarcer, being able to consume a lot of what was available may have allowed humans to store the calories necessary for harsher times ahead. In essence, such adjustments to abundance and the opposite adjustment to scarcity where less than expected quantities are eaten more slowly, using more bites and increasing satiation (Areni \& Black, 2015) can be seen as ways of making do with what one has, either by making a small quantity of food last longer psychologically (if not physically) or by making the most of a large quantity of food by storing as many calories as possible for future periods of scarcity.

The ability to adjust levels of satiation may be an adaptive mechanism designed to cope with unreliable food availability and allows both the psychological expansion of limited quantities so there is less desire for the food in the future, and the psychological contraction of larger quantities so more can be consumed. In essence, this can be viewed as the present self-improving the lot of the future self by altering the rate at which it consumes food but, unlike self-regulatory processes, it is not disadvantaged by doing so (Hoch \& Loewenstein, 1991; Ratner et al., 1999; Baumeister 2002). Eating more slowly does not decrease enjoyment when the available quantity is less than expected, and eating more quickly allows the present self to consume more when the available quantity is more than expected. Overall, therefore, this mechanism allows us to make the most of available resources both now and in the (uncertain) future.

Figure 1 illustrates this process as demonstrated by Areni and Black (2015). Participants began at point $\mathrm{P}$, being quite hungry and not yet having consumed any 
chocolate. They intended to consume six pieces of chocolate such that the sixth piece would leave them completely satiated at $\mathrm{F}_{\mathrm{X}}$. However, when participants in the small actual portion size condition were stopped unexpectedly after the second piece, and finished at point $F_{y}$, they were well short of their optimal level of satiation. However, when participants were told prior to eating the first piece that only two pieces were available, they were able to adjust the satiation function by eating more slowly in an attempt to reach complete satiation after the second piece at point Fz.

\section{$<$ Insert Figure 1 about here>}

The results of Study 1 reported here, essentially show this adaptive function operating in the opposite direction, as depicted in Figure 2. A participant begins at point $\mathrm{P}$, once again hungry and having not yet eaten their first piece. Those expecting to receive two pieces of chocolate initially attempted to consume them in such a way that the second piece would leave them optimally satiated at point $F_{X}$. When they were unexpectedly presented with four additional pieces of chocolate after consuming the second piece they were already, or were very close to being, completely satiated, so they could not eat the additional pieces.

However, participants who were told in advance that four additional pieces were available adjusted their satiation function by eating more quickly in an attempt to reach the optimal level of satiation after the sixth piece at point $F_{Y}$.

\section{$<$ Insert Figure 2 about here>}

In this case the benefit to the future self takes the form of lessening hunger rather than losing weight or maintaining a healthy diet. Although obesity is a serious problem in many developed and some emerging economies, for most of human history, lack of food 
and feelings of hunger were more serious concerns.

Many constraints (time, availability, money and concerns over obesity) prevent people from consuming to the point of satiation. These are often portrayed as conflicts between an impulsive, spontaneous present-oriented self, concerned with instant satisfaction, and a more disciplined future-oriented self, concerned with long-term happiness (Hoch \& Loewenstein 1991; Ratner et al. 1999; Baumeister 2002). The results reported here and those of Areni \& Black (2015), suggest that, rather than being in a state of conflict, present and future selves can cooperate with one another in subtle ways. When faced with compulsory reductions or increases in an enjoyable consumption experience the present-oriented self alters eating rates to achieve (i.e., smaller than expected portions) or maintain (i.e., larger than expected portions) satiation.

Future research would benefit by extending these findings to both other food contexts such as all you can eat buffets, communal eating (where a finite amount of food is available to feed people each with different portion size desires) and into non-food consumption. It is interesting to speculate about whether the present self can alter consumption rates to protect the future self from other negative affective states? As products' satiation can also be experienced as boredom, would a consumer who learns that they have only two rather than six lives left in a highly enjoyable video game play more conservatively to preserve those lives for longer (i.e., slower consumption rate)? Would they take more chances if they received four additional lives (i.e., faster consumption rate)?

In terms of practical implications, Wansink (2015) recently proposed the CAN (Convenience, Attractiveness and Normative) framework as a way to structure interventions designed to reduce the amount of food eaten and hence reduce obesity rates. This research and research supporting advice to diners to "eat slowly" and "take your time" (Johnson, 2012) suggests that the CAN model should be extended to include advice on adjusting eating rate. In 
particular, rather than chewing their food more, aspiring dieters might consider counting to ten before deciding whether to take the next piece of chocolate. 


\section{Anticipatory Savoring and Consumption}

\section{Reference}

Afifi, A. A., \& Clark, V. (1984). Computer-Aided Multivariate Analysis, Belmont, CA: Lifetime Learning Publications.

Allison, J. and Castellan, J. (1970). Temporal characteristics of nutritive drinking in rates and humans. Journal of Comparative and Physiological Psychology, 70(1), 116-125.

Andrade, A.M., Greene, G.W., \& Melanson, K.J. (2008). Eating slowly led to decreases in energy intake within meals in healthy women. Journal of the American Dietetic Association, 108, 1186-1191.

Angeles-Castellanos, M., Salgado-Delgado, R., Rodríguez, K., Buijs, R. M., \& Escobar, C. (2008). Expectancy for food or expectancy for chocolate reveals timing systems for metabolism and reward. Neuroscience, 155(1), 297-307.

Areni, C. S. (2008). (Tell me why) I don't like Mondays: Does an overvaluation of future discretionary time underlie reported weekly mood cycles? Cognition and Emotion, Cognition and Emotion, 22 (7), 1228-1252.

Areni, C. S. \& Black, I. R. (2015). Consumers' responses to small portions: signaling increases savoring and satiation. Psychology \& Marketing, 32(5), 532-543.

Baron, R. M. \& Kenny, D. A. (1986). The moderator-mediator distinction in social psychological research: conceptual, strategic, and statistical considerations. Journal of Personality and Social Psychology, 51(6), 1173-1182.

Baumeister, R.F. (2002). Yielding to temptation: self-control failure, impulsive purchasing, and consumer behavior. Journal of Consumer Research, 28(4), 670-676.

Bryant, F. B. (2003). Savoring Beliefs Inventory (SBI): A scale for measuring beliefs about savouring. Journal of Mental Health, 12 (2), 175-196.

Bryant, F. B. \& Veroff, J. (2007). Savoring: A New Model of Positive Experience, 


\section{Anticipatory Savoring and Consumption}

Mahwah, NJ: Lawrence Erlbaum Associates.

Epstein, L. H., Temple, J. L., Bouton, M. E., \& Roemmich, J. N. (2009). Habituation as a determinant of human food intake. Psychological Review, 116(2), 384-407.

Fisher, J. O., Rolls, B. J., \& Birch, L. L. (2003). Children's bite size and intake of an entrée are greater with large portions than with age-appropriate or self-selected portions. American Journal of Clinical Nutrition, 77(5), 1164-1170.

Forde, C. G., van Kuijk, N., Thaler, T., de Graaf, C., \& Martin, N. (2013). Oral processing characteristics of solid savory meal components, and relationship with food composition, sensory attributes and expected satiation. Appetite, 60, 208-219.

Galak, J., Kruger, J., \& Loewenstein, G. (2013). Slow down! Insensitivity to rate of consumption leads to avoidable satiation. Journal of Consumer Research, 39(5), 993 1009.

Galak, J., Redden, J. P., Yang, Y., \& Kyung, E. J. (2014). How perceptions of temporal distance influence satiation. Journal of Experimental Social Psychology, 52, 118-123.

Geier, A. B., Rozin, P., \& Doros, G. (2006). Unit bias: A new heuristic that helps explain the effect of portion size on food intake. Psychological Science, 17(6), 521-525.

Hill, S.W. \& McCutcheon, N.B. (1975). Eating responses of obese and non-obese humans during dinner meals. Psychosomatic Medicine, 37(5), 395-401.

Hoch, S.J. \& Loewenstein, G.F. (1991). Time-inconsistent preferences and consumer self- control. Journal of Consumer Research, 17, 492-507.

Inman, J. (2001). The role of sensory-specific satiety in attribute-level variety seeking. Journal of Consumer Research, 28 (1), pp. 105-120.

Johnson, C. (2012). 10 eating habits of the highly successful and fit. Women's Health, http://www.womenshealthmag.com/weight-loss/healthy-eating-habits (accessed: 19/9/16). 


\section{Anticipatory Savoring and Consumption}

Le Bel, J.L., \& Dube, L., (2001). Pleasures of different intensity levels: Properties of their online hedonic ratings and their impact on consumption behavior. In NA - Advances in Consumer Research Volume, 28, eds. Gilly, M.C., \& Meyers-Levy, J., Valdosta, GA : Association for Consumer Research, Pages: 411.

Loewenstein, G. (1987). Anticipation and the valuation of delayed consumption. The Economic Journal, 97(387), 666-684.

Kral, J. G., Biron, S., Simard, S., Hould, F. S., Lebel, S., Marceau, S., \& Marceau, P. (2006). Large maternal weight loss from obesity surgery prevents transmission of obesity to children who were followed for 2 to 18 years. Pediatrics, 118(6), e1644-e1649.

Macht, M., Meininger, J., \& Roth, J. (2005). The pleasures of eating: A qualitative analysis. Journal of Happiness Studies, 6(2), 137-160.

Mars, M., Hogenkamp, P. S., Gosses, A. M., Stafleu, A., \& De Graaf, C. (2009). Effect of viscosity on learned satiation. Physiology and Behaviour, 98(1), 60-66.

McAlister, L. (1982). A dynamic attribute satiation model of variety-seeking behavior. Journal of Consumer Research, 9, 141-150.

Mishra, A., Mishra, H., \& Masters, T. M. (2012). The influence of bite size on quantity of food consumed: a field study. Journal of Consumer Research, 38(5), 791-795.

Mitchell, T. R., Thompson, L., Peterson, E., \& Cronk, R. (1997). Temporal adjustments in the evaluation of events: The "rosy view". Journal of Experimental Social Psychology, 33, 421-448.

Nelson, L. D., \& Meyvis, T. (2008). Interrupted consumption: disrupting adaptation to hedonic experiences. Journal of Marketing Research, 45(6), 654-664.

Quoidbach, J., Dunn, E.W. Petrides, K.V. \& Mikolajczak, M. (2010). Money giveth, money taketh away: the dual effect of wealth on happiness. Psychological Science, 21(6), 759-763. 


\section{Anticipatory Savoring and Consumption}

Raynor, H. A. \& Epstein, L. H. (2001). Dietary variety, energy regulation, and obesity. Psychological Bulletin, 127(3), 325-341.

Ratner, R., Kahn, B.E. \& Kahneman, D. (1999). Choosing less-preferred experiences for the sake of variety, Journal of Consumer Research, 26(1), 1-15.

Rolls, B. J. (1986). Sensory-specific satiety. Nutrition reviews, 44(3), 93-101.

Rolls, Barbara J., Elizabeth A. Bell, and Bethany A. Waugh (2000), "Increasing the Volume of a Food by Incorporating Air Affects Satiety in Men," American Journal of Clinical Nutrition, 72 (2), 361-368.

Rolls, B. J., Morris, E. L., \& Roe, L. S. (2002). Portion size of food affects energy intake in normal-weight and overweight men and women. American Journal of Clinical Nutrition, 76(6), 1207-1213.

Rolls, B. J., Roe, L. S., Meengs, J. S., \& Wall, D. E. (2004). Increasing the portion size of a sandwich increases energy intake. Journal of the American Dietetic Association, 104(3), 367-372.

Rozin, P., Kabnick, K., Pete, E., Fischler, C., \& Shields, C. (2003). The ecology of eating: smaller portion sizes in France than in the United States help explain the French paradox. Psychological Science, 14(5), 450-454.

Rugh, J. D. (1972). Variation in human masticatory behavior under temporal constraints. Journal of Comparative and Physiological Psychology, 80(1), 169-174.

Sevilla, J., \& Redden, J. P. (2014). Limited Availability Reduces the Rate of Satiation. Journal of Marketing Research, 51(2), 205-217.

Soper, D. (2015). Statistics Calculators Version 3.0, http://www.danielsoper.com/statcalc3/calc.aspx?id=31 (accessed: 21/12/15).

Viskaal-van Dongen, M., F. J. Kok, \& C. de Graaf. (2011) "Eating Rate of Commonly Consumed Foods Promotes Food and Energy Intake". Appetite, 56(1), 25-31 


\section{Anticipatory Savoring and Consumption}

Vohs, K.D., \& Heatherton, T.F. (2000). Self-Regulatory failure: a resource-depletion approach. Psychological Science, 11, 249-254.

Wansink, B. (2004). Environmental factors that increase the food intake and consumption volume of unknowing consumers. Annual Review of Nutrition, 24, 455-479.

Wansink, B., Painter, J. E., \& North, J. (2005). Bottomless bowls: why visual cues of portion size may influence intake. Obesity Research, 13(1), 93-100.

Wansink, B. (2015). Change their choice! Changing behavior using the CAN approach and activism research. Psychology \& Marketing, 32(5), 486-500.

Zijlstra, N., Mars, M., de Wijk, R. A., Westerterp-Plantenga, M. S., \& de Graaf, C. (2008). The effect of viscosity on ad libitum food intake. International Journal of Obesity, 32(4), 676-683.

Zijlstra, N., de Wijk, R. A., Mars, M., Stafleu, A., \& de Graaf, C. (2009). Effect of bite size and oral processing time of a semisolid food on satiation. American Journal of Clinical Nutrition, 90(2), 269-275.

Zlatevska, N., Dubelaar, C., \& Holden, S. S. (2014). Sizing up the effect of portion size on consumption: A meta-analytic review. Journal of Marketing,78(3), 140-154. 


\section{Anticipatory Savoring and Consumption}

Figure 1: How Changes in Expected Quantities Affect Eating Rate and Satiation Level: Scarcity

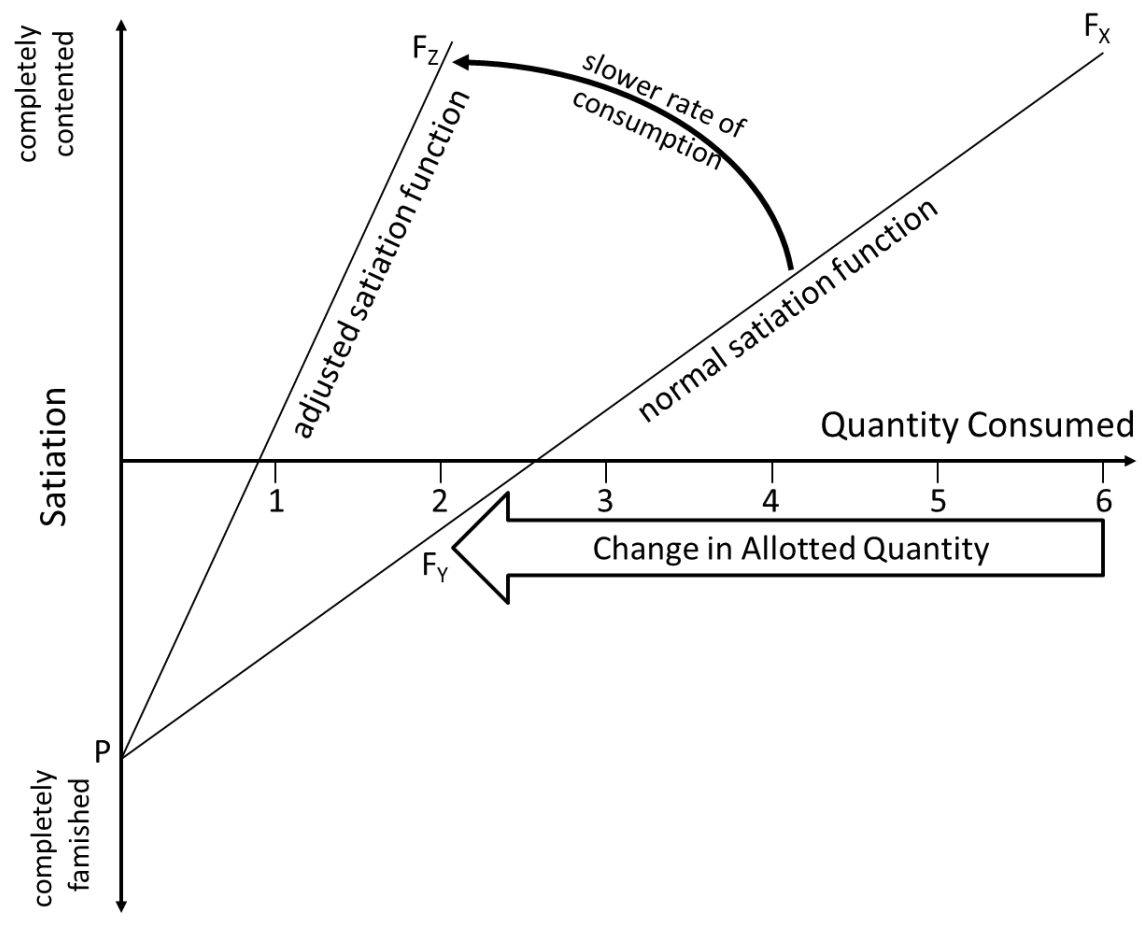




\section{Anticipatory Savoring and Consumption}

Figure 2: How Changes in Expected Quantities Affect Eating Rate and Satiation Level:

Abundance

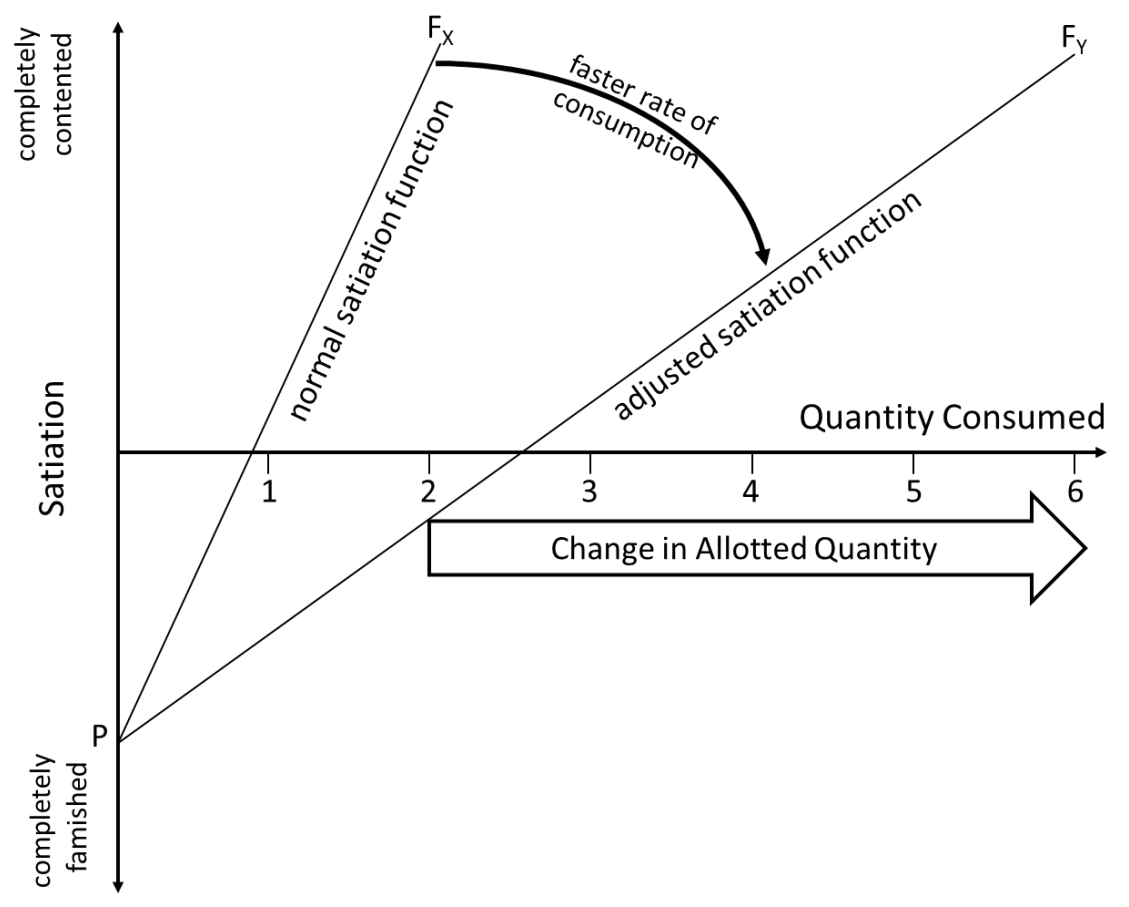

